\title{
Phosphatidylinositol 3-Kinase Regulates Macrophage Responses to Double-Stranded RNA and Encephalomyocarditis Virus
}

\author{
Wieke Freudenburg $^{a}$ Jason M. Moran ${ }^{a} \quad$ Nathan H. Lents ${ }^{b} \quad$ Joseph J. Baldassare \\ R. Mark L. Buller ${ }^{d}$ John A. Corbett ${ }^{\mathrm{e}}$ \\ ${ }^{a}$ Edward A. Doisy Department of Biochemistry and Molecular Biology, Saint Louis University School of Medicine, \\ St. Louis, Mo., b Department of Sciences, John Jay College, The City University of New York, New York, N.Y., \\ 'Department of Pharmacology and Physiology, and d Department of Molecular Microbiology and Immunology, \\ Saint Louis University School of Medicine, St. Louis, Mo., ${ }^{e}$ Comprehensive Diabetes Center, Department \\ of Medicine, Division of Endocrinology Diabetes and Metabolism, University of Alabama at Birmingham, \\ Birmingham, Ala., USA
}

\section{Key Words}

Inflammation • Innate immunity - Macrophages •

Nitric oxide $\cdot$ Virus infection

\begin{abstract}
Virus infection of macrophages stimulates the expression of proinflammatory and antiviral genes interleukin-1 (IL-1), inducible nitric oxide synthase (iNOS) and cyclooxygenase-2 (COX-2). In this study, we show that phosphatidylinositol 3kinase (PI3K) is required for the inflammatory response of macrophages to virus infection. When macrophages are infected with encephalomyocarditis virus (EMCV) there is a rapid and transient activation of $\mathrm{PI} 3 \mathrm{~K}$ and phosphorylation of its downstream target Akt. Inhibitors of PI3K attenuate EMCVand double-stranded RNA-induced iNOS, COX-2 and IL-1 $\beta$ expression in RAW264.7 cells and mouse peritoneal macrophages. The attenuation of inflammatory gene expression in response to PI3K inhibition correlates with the induction of macrophage apoptosis. The morphology of macrophages shifts from activation in response to EMCV infection to apoptosis in the cells treated with PI3K inhibitors and EMCV. These morphological changes are accompanied by the activation of caspase-3. These findings suggest that PI3K plays a central role in the regulation of macrophage responses to EMCV in-
\end{abstract}

fection. When PI3K is activated, it participates in the regulation of inflammatory gene expression; however, if PI3K is inhibited macrophages are unable to mount an inflammatory antiviral response and die by apoptosis.

Copyright $\odot 2009$ S. Karger AG, Basel

\section{Introduction}

Virus infection of macrophages results in the expression of proinflammatory and antiviral genes that include interleukin-1 (IL-1), inducible nitric oxide synthase (iNOS) and cyclooxygenase-2 (COX-2) $[1,2]$. The expression of iNOS and subsequent production of nitric oxide plays a primary role in the cellular response to virus infection. Nitric oxide attenuates virus infection by nitrosylation and inactivation of viral proteins required for replication [3,4]. Virus infection of iNOS-deficient mice results in reduced viral clearance and higher mortality rates compared to wild-type controls $[5,6]$. COX-2 catalyzes the oxidation of arachidonic acid to prostaglandin $\mathrm{H}_{2}$, which is subsequently isomerized to various pros-

W.F. and J.M.M. contributed equally to this work.

\section{KARGER}

() 2009 S. Karger AG, Basel

Fax +4161306 1234

E-Mail karger@karger.ch

www.karger.com
Accessible online at: www.karger.com/jin
Dr. John A. Corbett

Department of Medicine, Division of Endocrinology Diabetes and Metabolism

The Comprehensive Diabetes Center, University of Alabama Birmingham

12 Floor Shelby, 1530 3rd Ave. South, Birmingham, AL 35294-2182 (USA)

Tel. +1 205996 9546, Fax +1 205996 5220, E-Mail corbettj@UAB.edu 
tanoids. Prostaglandins generated by COX-2 participate in the cellular response to virus infection by modulating virus replication [7].

Recent studies have identified a number of pathways involved in the regulation of inflammatory gene expression in macrophages treated with doubled-stranded RNA (dsRNA) or encephalomyocarditis virus (EMCV). EMCV is a picornavirus that has been used as a prototype virus to study antiviral responses [8]. Nuclear factor (NF)- $\kappa B$ plays a primary role in regulating macrophage expression of iNOS, COX-2 and IL-1 in response to EMCV and synthetic dsRNA (poly IC) $[1,2,9]$. NF- $\kappa$ B is held in the cytoplasm in an inactive complex with inhibitory protein $(\mathrm{I}) \kappa \mathrm{K}$. Following phosphorylation by an IкB kinase (IKK), ІкB is targeted for degradation, allowing NF- $\mathrm{B}$ to translocate to the nucleus to activate gene expression [10]. In addition to NF- $\kappa \mathrm{B}$, the activation of a secondary signaling pathway that is selective for the target gene of interest is also required for EMCV- and poly IC-induced inflammatory gene expression by macrophages. These secondary signaling pathways include extracellular signal-regulated kinase (ERK) activation for IL-1 $\beta$ expression [9], PLA $_{2}$ activation for iNOS [11] and Jun N-terminal kinase (JNK) and p38 activation for COX-2 [12]. The regulation of inflammatory gene expression in response to EMCV and dsRNA appears to be independent of the dsRNA-dependent protein kinase (PKR), a dsRNA sensor that initiates various antiviral responses $[9,13,14]$. These studies suggest that virus-induced proinflammatory gene expression is dependent on the activation of NF- $\kappa \mathrm{B}$ and a second signaling cascade that is selective for the target gene of interest.

Phosphatidylinositol 3-kinase (PI3K) is a lipid kinase composed of an Src homology 2 domain containing a 85$\mathrm{kDa}$ regulatory subunit (p85) and a $110-\mathrm{kDa}$ catalytic subunit (p110) [15]. PI3K is activated in response to growth factors, cytokines and other stimuli and regulates diverse cellular functions, including proliferation and survival [15]. Virus infection has been shown to activate PI3K [16-19] and this activation appears to favor viral replication by preventing host cell death, suggesting that viruses utilize host PI3K to enhance viral survival [20]. However, the role of PI3K in host cell defense is not well defined although PI3K has been shown to be required for nitric oxide production by activated macrophages [21]. Since nitric oxide plays a primary role in host defense against virus infection, we examined the role of PI3K in the regulation of virus-induced nitric oxide production by macrophages. We show that inhibition of PI3K attenuates dsRNA- and EMCV-induced iNOS expression and nitric oxide production. The regulatory role of PI3K does not appear to be selective for iNOS, as inhibition of PI3K attenuates dsRNA- and EMCV-induced COX-2 and IL-1 expression as well. In addition to its role in the regulation of inflammatory genes, PI3K also exerts antiapoptotic functions by preventing macrophage apoptosis following virus infection. These findings suggest that virus-induced PI3K activity is required for the inflammatory response of macrophages to virus infection. Inhibition of PI3K signaling attenuates the inflammatory response and results in macrophage apoptosis.

\section{Materials and Methods}

\section{Materials and Animals}

RAW264.7 cells, L929 cells, RINm5F cells, Dulbecco's modified Eagle's medium (DMEM; containing 10\% heat-inactivated fetal calf serum and $1 \times$ L-glutamine) and RPMI medium (containing $10 \%$ heat-inactivated fetal calf serum, $1 \times$ L-glutamine, $100 \mathrm{units} / \mathrm{ml}$ penicillin and $100 \mu \mathrm{g} / \mathrm{ml}$ streptomycin) were all obtained from Washington University Tissue Culture Support Center (St. Louis, Mo., USA). C57BL/6J mice were purchased from Harlan (Indianapolis, Ind., USA). Mouse recombinant IFN- $\gamma$ was obtained from R\&D Systems (Minneapolis, Minn., USA). Poly IC was purchased from Sigma Chemical Co. (St. Louis, Mo., USA) and prepared as previously described. LY294002 was purchased from Calbiochem (La Jolla, Calif., USA). Rabbit anti-iNOS antiserum was generously provided by Dr. Pam Manning (Pfizer, St. Louis, Mo., USA). Rabbit anti-COX-2 antiserum was obtained from Cayman Chemical (Ann Arbor, Mich., USA). 3ZD monoclonal mouse anti-IL-1 $\beta$ was from Biological Resources Branch, DCTD at the NCI. Rabbit anti-phospho-Akt (Ser473) was obtained from BioSource (Camarillo, Calif., USA) and from Cell Signaling (Beverly, Mass., USA). Mouse anti-GAPDH was purchased from Ambion (Austin, Tex., USA). Horseradish-peroxidase-conjugated donkey anti-rabbit and donkey anti-mouse antibodies were obtained from Jackson ImmunoResearch (West Grove, Pa., USA). PCR primers for iNOS, IL-1 $\beta$, EMCV and GAPDH were purchased from Integrated DNA Technologies (Coralville, Iowa, USA). Wild-type and dominant negative p $85 \alpha$ have been previously described [22]. All other reagents were obtained from commercially available sources. The Saint Louis University Institutional Review Board has approved all animal studies contained within this report.

\section{Peritoneal Macrophage Isolation and Cell Culture}

Peritoneal exudate cells (PECs) were obtained from wild-type C57BL/6J mice by peritoneal lavage as described previously [23]. Following isolation, $4 \times 10^{5}$ cells $/ 400 \mu$ l complete CMRL-1066 were incubated at $37^{\circ} \mathrm{C}$ under an atmosphere of $95 \%$ air and $5 \%$ $\mathrm{CO}_{2}$. Cells were washed 3 times with complete CMRL-1066 to remove nonadherent cells before treating with poly IC or EMCV.

RAW264.7 cells were removed from growth flasks by treatment with $0.05 \%$ trypsin, $0.02 \%$ EDTA at $37^{\circ} \mathrm{C}$, washed with DMEM and plated at the indicated concentration. Macrophages were cultured for a minimum of $2 \mathrm{~h}$ under an atmosphere of $95 \%$ air and $5 \% \mathrm{CO}_{2}$ prior to the initiation of experiments. 
Virus Propagation and Infection

The B variant of EMCV was a generous gift from Dr. Ji-Won Yoon (University of Calgary, Calgary, Alta., Canada) and has been described previously [24]. EMCV was propagated in L929 cells, supernatants were clarified by centrifugation, and titers were determined by standard plaque assay. Cell monolayers were infected at a multiplicity of infection of $1 \mathrm{PFU} /$ cell by the addition of EMCV to the culture medium at $37^{\circ} \mathrm{C}$ for the times indicated.

\section{PI3K Activity Assay}

The enzymatic activity of PI3K was measured as previously described [25]. Briefly, RAW264.7 cells were infected with EMCV for the indicated times, cell lysates were harvested and p85 immune complexes were enriched by immunoprecipitation. Immunoprecipitates were washed and subsequently incubated with phosphatidylinositol and $\left[\gamma-{ }^{32} \mathrm{P}\right] \mathrm{ATP}$ in reaction buffer for $10 \mathrm{~min}$ at $37^{\circ} \mathrm{C}$. After termination of the reaction by the addition of $\mathrm{HCl}$, lipids were extracted and resolved by thin-layer chromatography. Phosphatidylinositol-3-phosphate production was quantified using a PhosphorImager ${ }^{\mathrm{TM}}$ (Molecular Dynamics).

\section{Nitrite and IL-1 Determination}

Nitrite production was determined by the addition of $50 \mu \mathrm{l}$ Greiss reagent to $50 \mu \mathrm{l}$ macrophage cell culture supernatant [26]. Absorbance at $540 \mathrm{~nm}$ was measured and nitrite concentrations were quantified by comparison to a sodium nitrite standard curve. The release of bioactive IL-1 from macrophages was measured using the RINm5F cell bioassay as previously described [27]. Briefly, macrophage supernatants were diluted (1:50 to 1:200) in RPMI and $20 \mu \mathrm{l}$ was added to RINm5F cells $\left(2 \times 10^{5}\right.$ cells/180 $\mu \mathrm{l}$ RPMI). Following a 24 -hour culture, IL-1-induced nitrite production by RINm5F cells was determined using the Greiss assay as described above and IL-1 concentrations were calculated from an IL-1 standard curve.

\section{Western Blot Analysis}

Protein samples were separated under denaturing conditions by sodium dodecylsulfate-polyacrylamide gel electrophoresis and transferred to nitrocellulose (GE Healthcare, Piscataway, N.J., USA) or PVDF (Pall Life Sciences, Pensacola, Fla., USA) membranes under semidry transfer conditions. Antibody dilutions were as follows: mouse anti-pro-IL-1 $\beta, 1: 2,000$; rabbit antiCOX-2 1:2,000; mouse anti-GAPDH, 1:5,000; all other primary antibodies were used at 1:1,000. Horseradish-peroxidase-conjugated donkey anti-mouse and donkey anti-rabbit secondary antibodies were used at 1:5,000 and 1:7,000 dilution, respectively. Antigen was detected by chemoluminescence according to the manufacturer's specifications (GE Healthcare).

\section{Real-Time PCR}

Total RNA was isolated from macrophages using the RNeasy kit according to the manufacturer's instructions (Qiagen, Valencia, Calif, USA). First-strand cDNA synthesis was performed using oligo(dT) and a reverse transcriptase Superscript preamplification system (Invitrogen, Carlsbad, Calif., USA) following the manufacturer's recommendations. Real-time PCR was performed using iQ SYBR Green Supermix (Bio-Rad, Hercules, Calif., USA) and a Research DNA Engine Opticon II thermocycler with continuous fluorescence detection (MJ Research, Waltham, Mass., USA). The mRNA levels of dsRNA- and EMCV-induced genes were normalized to GAPDH. PCR primer sequences for COX-2 were: forward primer 5'-TTT GTT GAG TCA TTC ACC AGA CAG AT-3' and reverse primer 5'-CAG TAT TGA GGA GAA CAG ATG GGA TT-3'. PCR primers for iNOS, IL-1, and GAPDH have all been described [28].

\section{Transfection}

RAW264.7 cells were transiently transfected using the Amaxa Nucleofector electroporator (Amaxa Biosystems, Gaithersburg, Md., USA). RAW264.7 cells were removed from growth flasks by treatment with $0.05 \%$ trypsin and $0.02 \%$ EDTA at $37^{\circ} \mathrm{C}$, washed with DMEM, and incubated for $2 \mathrm{~h}$ at $37^{\circ} \mathrm{C} .2 \times 10^{6}$ cells were resuspended in electroporation buffer and electroporated with $2 \mu \mathrm{g}$ of plasmid using program D-032. $4 \times 10^{5}$ cells $/ 400 \mu \mathrm{l}$ DMEM were plated per condition. Six hours after transfection, the medium was replaced and the cells were cultured overnight at $37^{\circ} \mathrm{C}$. The cells were washed twice with DMEM before initiation of experiments. Transfection efficiency of greater than $50 \%$, as determined by electroporation with enhanced green fluorescent protein were routinely obtained using this methodology.

\section{Caspase-3 Activity}

RAW264.7 cells $\left(2 \times 10^{5} / 400 \mu \mathrm{l}\right.$ DMEM $)$ were pretreated with LY294002 for $1 \mathrm{~h}$; EMCV, poly IC or camptothecin were added and the cells were cultured for an additional $24 \mathrm{~h}$. Caspase- 3 activity was determined using a caspase- 3 fluorometric assay kit according to the manufacturer's instructions (R\&D Systems). The relative fluorescence units were normalized to total protein content of each sample as determined by the BCA assay (Pierce, Rockford, Ill., USA). Data are presented as fold-increase over the untreated control.

\section{Statistics}

Statistical comparisons between groups were made using oneway ANOVA. Significant differences between groups $(\mathrm{p}<0.05)$ were determined using a Newman-Keuls post hoc analysis.

\section{Results}

\section{EMCV and dsRNA Activate PI3K in Macrophages}

To evaluate the effects of EMCV infection and poly IC treatment on PI3K activation, the phosphorylation of Akt was examined by Western blot analysis. EMCV infection of RAW264.7 cells for 20 min results in a $3.7 \pm 0.6$-fold increase in Akt phosphorylation compared to untreated controls (mean \pm SEM of 4 independent experiments). The stimulatory actions of EMCV on Akt phosphorylation are transient, with phosphorylation persisting for 15 min to $2 \mathrm{~h}$ after infection (fig. 1a). PI3K activation returns to basal levels 3-4 h after infection as evidenced by the return of Akt to basal levels of phosphorylation. The synthetic dsRNA poly IC also stimulates Akt phosphorylation in a fashion similar to EMCV infection (fig. 1b). Inhibition of PI3K using LY294002 attenuates the stimulatory actions of EMCV or dsRNA on Akt phosphorylation (fig. 1b). 

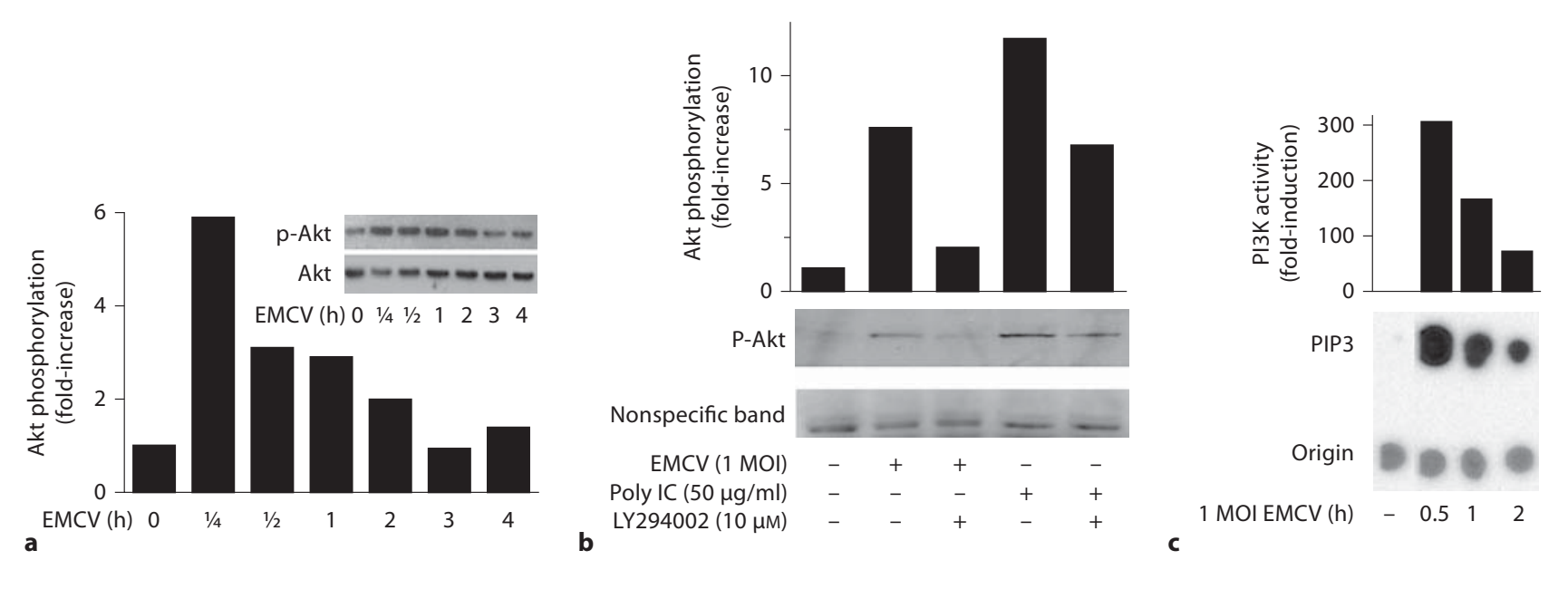

Fig. 1. EMCV infection of macrophages activates PI3K. RAW264.7 cells $\left(4 \times 10^{5} / 400 \mu \mathrm{l}\right.$ DMEM $)$ were treated for the indicated times with EMCV (a) or for $15 \mathrm{~min}$ with poly IC $(50 \mu \mathrm{g} / \mathrm{ml}$; b), the cells were harvested and Akt phosphorylation was determined by Western blot analysis. Total Akt (a) and a nonspecific band (b) are shown as a loading control and results were quantified using Im-

The ability of LY294002 to attenuate Akt Ser473 phosphorylation in response to EMCV infection and poly IC treatment may be indirectly mediated by the inhibition of PDK1 Thr308 phosphorylation of Akt [29]. Therefore, to confirm that Akt phosphorylation correlates with PI3K activation, an immuno-complex kinase assay for PI3K activation was performed on EMCV-infected RAW264.7 cells. Consistent with Akt phosphorylation, EMCV stimulates a rapid activation of PI3K that was first measured 30 min after infection (fig. 1c). PI3K activity returns to near basal levels $2 \mathrm{~h}$ after infection. This rapid activation is consistent with the rapid stimulation of PI3K activity 30 min after HCMV infection [17].

\section{PI3K Inhibition Attenuates EMCV-Stimulated Nitrite}

Production and $i N O S, I L-1 \beta$ and COX-2 Expression

by Macrophages

To determine whether PI3K participates in the regulation of the inflammatory response of macrophages, the effects of PI3K inhibition on EMCV-induced iNOS, COX2 and IL-1 $\beta$ expression were examined. As show in figure 2a, LY294002 attenuates EMCV-induced iNOS expression and nitrite formation by RAW264.7 cells in a concentration-dependent manner with maximal inhibition at $10 \mu \mathrm{M}$. Similar to iNOS, EMCV-induced IL-1 $\beta$ and COX-2 expressions are also attenuated by this PI3K
ageQuant software. RAW264.7 cells $\left(4 \times 10^{5} / 400 \mu\right.$ l DMEM) were infected with EMCV (1 MOI) for the times indicated and PI3K enzymatic activity was determined by the incorporation of radiolabeled phosphate into phosphatidylinositol-3,4,5-triphosphate (PIP3) (c). Incorporation was quantified by autoradiography. Results are representative of 3 independent experiments.

inhibitor (fig. 2b, c). Primary naïve PECs require two proinflammatory signals for iNOS expression $[13,30]$. As shown in figure $2 \mathrm{~d}$, in combination with IFN- $\gamma, \mathrm{EMCV}$ stimulates iNOS expression and nitrite production by PECs. Inhibition of PI3K using LY294002 attenuates EMCV + IFN- $\gamma$-stimulated iNOS expression and nitrite production by primary mouse macrophages.

The effects of LY294002 on EMCV-stimulated iNOS, COX-2 and IL-1 mRNA accumulation following $6 \mathrm{~h}$ incubation were evaluated by real-time PCR. Infection of RAW264.7 cells with EMCV stimulates the accumulation of iNOS, COX-2 and IL-1 $\beta$ mRNA. At a concentration of $10 \mu \mathrm{M}, \mathrm{LY} 294002$ attenuates the stimulatory actions of EMCV on iNOS, COX-2, and IL- $1 \beta$ mRNA accumulation by greater than $50 \%$ (fig. 3). These findings suggest that inflammatory gene expression in response to EMCV infection is mediated, in part, by PI3K activation.

\section{PI3K Inhibition Attenuates dsRNA-Induced Nitrite \\ Production and $i N O S, I L-1 \beta$ and COX-2 Expression by Macrophages}

In macrophages, EMCV and poly IC have been shown to stimulate inflammatory gene expression by similar mechanisms $[1,2]$. Consistent with a role for PI3K in the regulation of inflammatory gene expression following 
Fig. 2. PI3K inhibition attenuates EMCV-induced macrophage activation. RAW264.7 cells $\left(2 \times 10^{5}\right.$ or $4 \times 10^{5} / 400$ $\mu \mathrm{l}$ DMEM; a, b) or mouse PEC $\left(4 \times 10^{5}\right.$ cells/400 $\mu$ l cCMRL-1066; c, d) were pretreated with the indicated concentrations of LY294002 or vehicle control for $1 \mathrm{~h}$ at $37^{\circ} \mathrm{C}$. The macrophages were infected with EMCV (1 MOI) and $24 \mathrm{~h}$ after infection, nitrite production in culture supernatants was quantified by Greiss assay (a, d), and iNOS (a, d), COX-2 (b), and IL-1 $\beta$ (c) expression was determined by Western blot analysis. Results are the average \pm SEM or representative of 3 independent experiments. ${ }^{*} \mathrm{p} \leq 0.05$.

Fig. 3. PI3K inhibition attenuates EMCVstimulated inflammatory gene expression. RAW264.7 cells $\left(2 \times 10^{5} / 400 \mu\right.$ l DMEM $)$ were pretreated with the indicated concentrations of LY294002 for $1 \mathrm{~h}$ at $37^{\circ} \mathrm{C}$ followed by the addition of EMCV (1 MOI) and cultured for an additional $6 \mathrm{~h}$. The cells were harvested, total RNA isolated, and iNOS, COX-2, and IL-1 $\beta$ mRNA accumulation was determined by real-time PCR. mRNA accumulation was normalized to GAPDH. Results are the mean \pm SEM for 3 independent experiments.
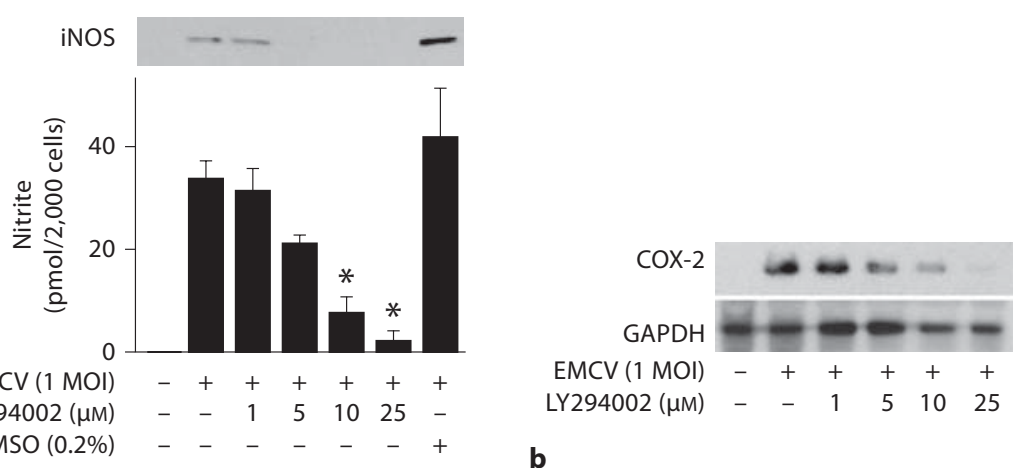

a

LY294002 $(\mu \mathrm{M}) \quad-\quad-\quad 151025 \quad-$

b
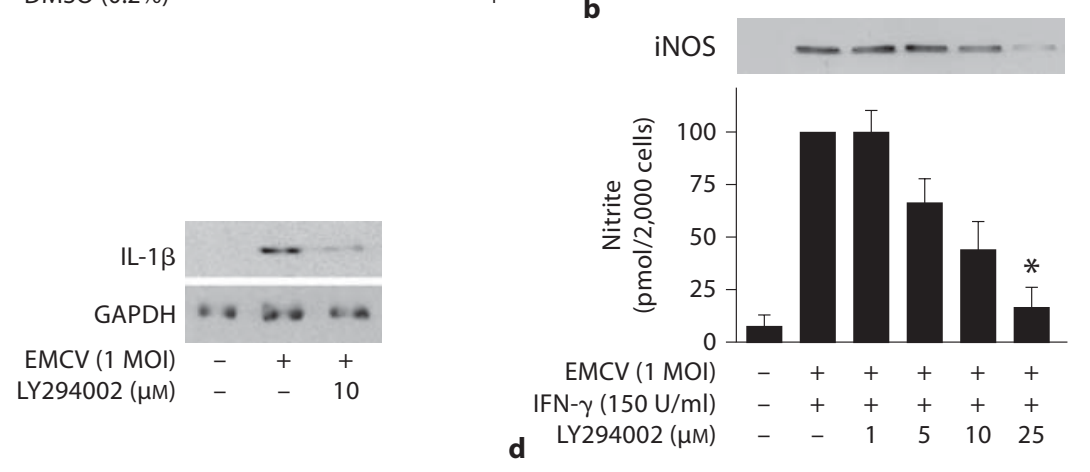

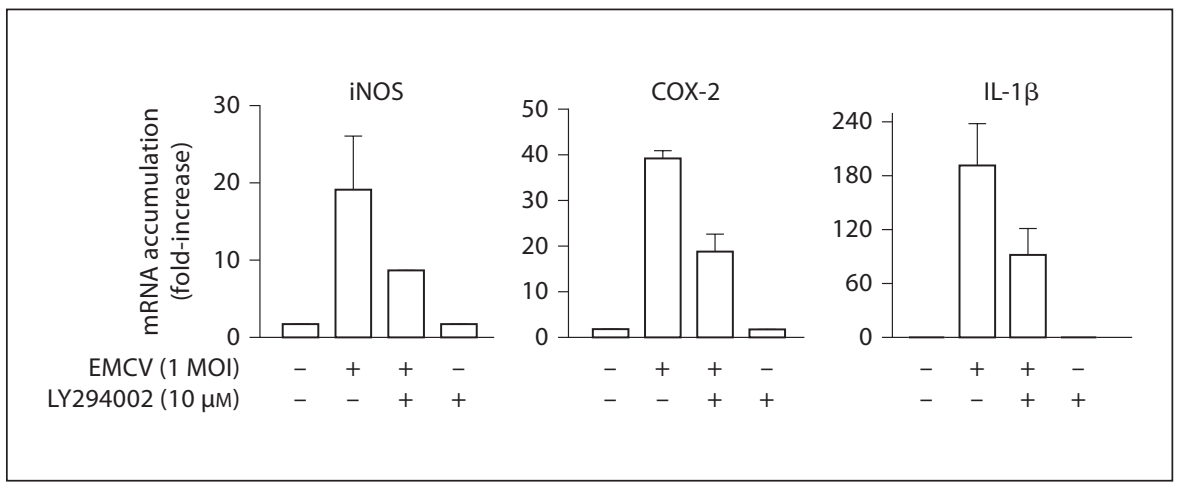

EMCV infection, LY294002 attenuates dsRNA-induced nitrite production and the release of biologically active IL-1 from RAW264.7 cells (fig. 4a, b). Inhibition of PI3K activity also attenuates poly-IC-stimulated RAW264.7 cell iNOS, COX-2 and IL-1 $\beta$ mRNA accumulation following $6 \mathrm{~h}$ incubation (fig. $4 \mathrm{c}$ ) and protein expression following $24 \mathrm{~h}$ incubation (fig. $4 \mathrm{~d}$ ).

\section{Expression of dnPI3K Attenuates EMCV-Stimulated Inflammatory Gene Expression}

To provide molecular confirmation for a role for PI3K in the regulation of inflammatory gene expression,
RAW264.7 cells were transiently transfected with a vector encoding a mutant of the p $85 \alpha$ subunit lacking a binding site for the catalytic subunit of PI3K [22]. Using COX-2 as a target inflammatory gene, we show that EMCV infection of RAW264.7 cells expressing the empty vector control results in expression of COX-2 (24 h) and phosphorylation of the Akt (15 min, fig. 5). RAW264.7 cells expressing the dominant negative p $85 \alpha$ mutant fail to express COX-2 in response to EMCV infection $(24 \mathrm{~h})$ and this effect correlates with attenuation of the stimulatory actions of $15 \mathrm{~min}$ infection on Akt phosphorylation (fig. 5b). 


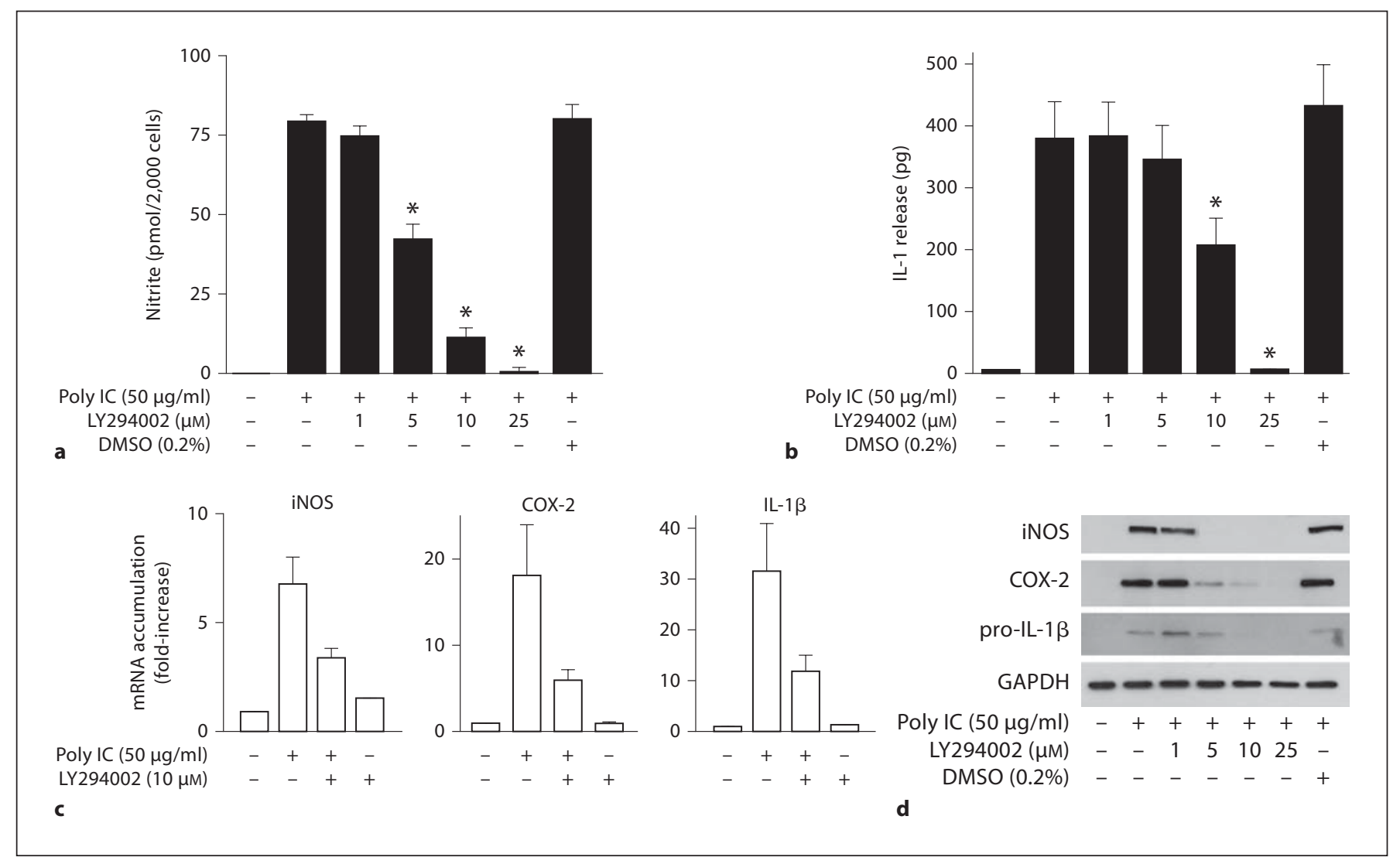

Fig. 4. PI3K inhibition attenuates dsRNA-induced nitrite production, IL- 1 release, and iNOS, IL- $1 \beta$ and COX- 2 expression by macrophages. RAW264.7 cells $\left(4 \times 10^{5} / 400 \mu\right.$ l DMEM $)$ were pretreated with the indicated concentrations of LY294002 for $1 \mathrm{~h}$, poly IC $(50 \mu \mathrm{g} / \mathrm{ml})$ was added and cells were cultured for an additional $24 \mathrm{~h}(\mathbf{a}, \mathbf{b}, \mathbf{d})$. Culture supernatants were collected and analyzed for nitrite production (a) and the release of biologically active IL1 (b). The cells were harvested, and iNOS, IL-1 $\beta$ and COX-2 expression was determined by Western blot analysis (d). GAPDH is shown as a loading control. The accumulation of iNOS, COX-2 and IL- $1 \beta$ mRNA was determined by real-time PCR on total RNA isolated from RAW264.7 cells $\left(2 \times 10^{5} / 400 \mu\right.$ l DMEM) pretreated with or without the indicated concentrations of LY294002 for $1 \mathrm{~h}$ followed by a 6 -hour incubation with poly IC $(50 \mu \mathrm{g} / \mathrm{ml})(\mathbf{c})$. Results are the average \pm SEM $(\mathbf{a}-\mathbf{c})$ or representative $(\mathbf{d})$ of three independent experiments. * Statistical significance was reported when $\mathrm{p} \leq 0.05$.

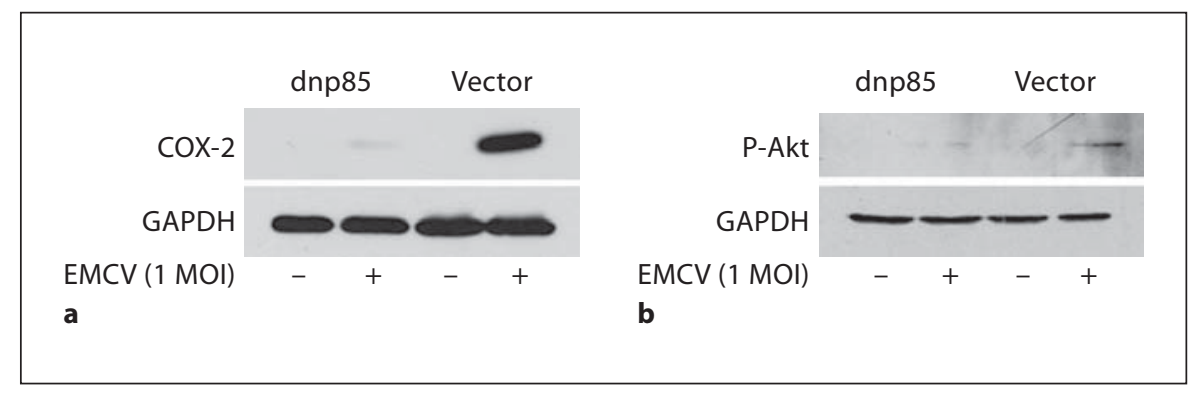

Fig. 5. Expression of a dnPI3K mutant attenuates EMCV-induced inflammatory gene expression. RAW264.7 cells $\left(2 \times 10^{6}\right)$ were electroporated with $2 \mu \mathrm{g}$ of dominant negative p $85 \alpha$ plasmid or with a vector control. Transfected cells $\left(4 \times 10^{5} / 400 \mu \mathrm{l}\right.$ DMEM) were treated with EMCV (1 MOI) for $24 \mathrm{~h}$ (a) or for $15 \mathrm{~min}$ (b).
The cells were harvested and COX-2 (a) and phospho-Akt (b) expression was determined by Western blot analysis. GAPDH is shown as a loading control. Results are representative of 2 independent experiments. 

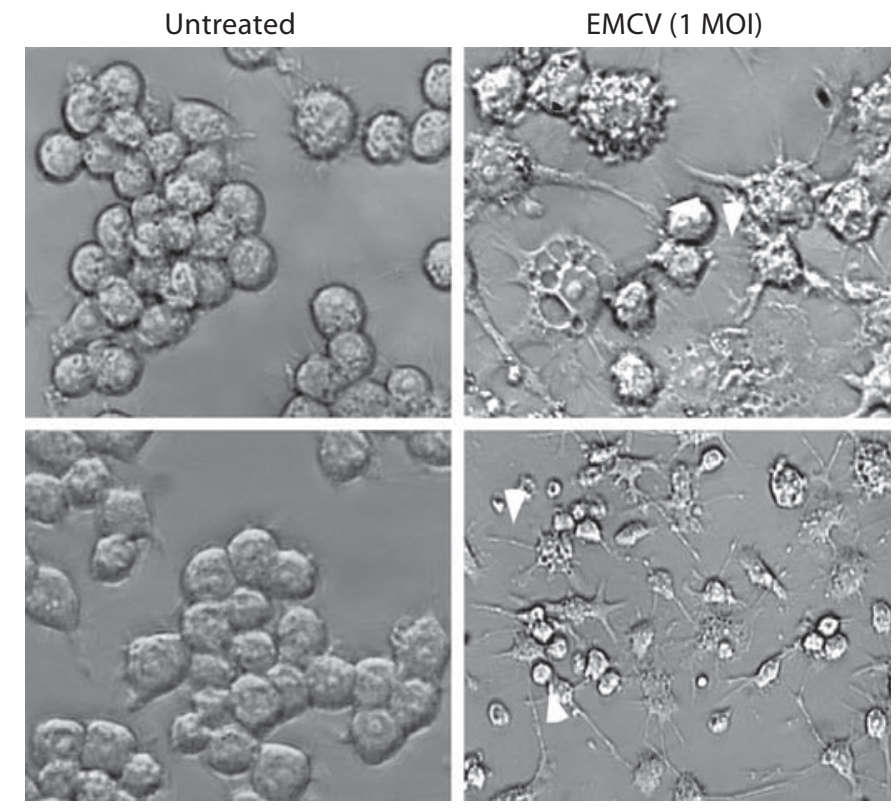

a

$\operatorname{LY} 294002(10 \mu \mathrm{M})$

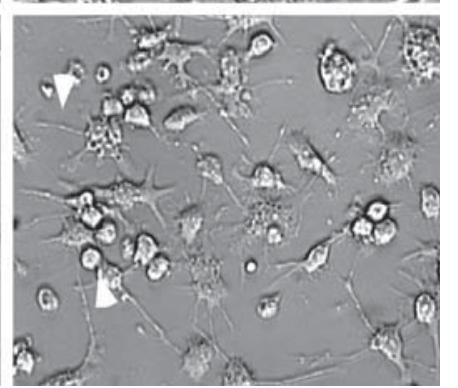

$\mathrm{EMCV}+\mathrm{LY} 294002$

Fig. 6. Inhibition of PI3K results in the death in EMCV-infected macrophages. RAW264.7 cells $\left(2 \times 10^{5} / 400 \mu\right.$ l DMEM) were incubated for $24 \mathrm{~h}$ with $10 \mu \mathrm{M}$ LY294002 or EMCV (1 MOI) or preincubated for $1 \mathrm{~h}$ with LY294002 followed by the addition of EMCV and continued culture for $24 \mathrm{~h}$. Macrophage morphology was examined by phase contrast microscopy (original magnifica-

\section{Effects of PI3K Inhibition on the Viability of}

EMCV-Infected Macrophages

Macrophage activation is associated with morphological changes that include rounding and ruffling of the cell surface and the formation of dendrite-like processes. As expected, the morphological changes observed in RAW264.7 cells $24 \mathrm{~h}$ after EMCV infection are consistent with robust macrophage activation (fig. 6a). Alone, inhibitors of PI3K, at concentrations that attenuate macrophage expression of inflammatory genes in response to EMCV infection (fig. 2), do not modify the quiescent morphology of untreated macrophages. In contrast, inhibition of PI3K (using LY924002) in macrophages infected with EMCV results in dramatic morphological changes that are consistent with induction of cell death by apoptosis. The formation of long dendrite-like processes and ruffled cell membranes is attenuated, and the cells condensate. PI3K is a critical regulator of cell survival in many cell types, including macrophages [31], that when active is known to prevent apoptotic cell death $[15,32]$. Therefore we examined the effects of PI3K inhibition on caspase-3 activity in EMCV-infected macrophages. Cas-

PI3K Regulates Macrophage Responses to dsRNA and EMCV

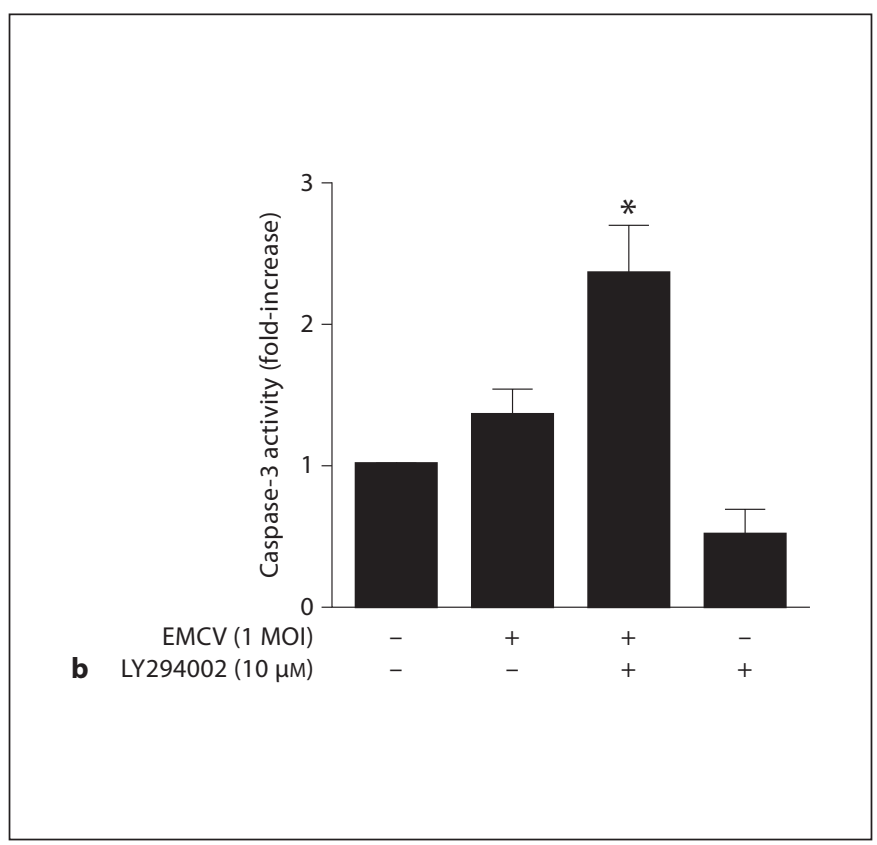

tion $40 \times$; a), or the cells were harvested and caspase-3 activity was determined (b). Caspase activity was normalized to total protein content and is presented as fold-increase over control. Results are representative or the average \pm SEM of 3 independent experiments. ${ }^{*} \mathrm{p} \leq 0.05$.

pase- 3 is an executioner caspase that is activated in both the intrinsic and extrinsic pathways of apoptosis [33]. Consistent with morphological changes associated with apoptosis, there is a 2 -fold increase in caspase-3 activity in RAW264.7 cells pretreated for $1 \mathrm{~h}$ with LY294002 followed by $24 \mathrm{~h}$ infection with EMCV (fig. 6b). The measured fold-increase in caspase activity under these conditions is likely an underestimate of total caspase activation as $10 \mu \mathrm{M}$ LY294002 attenuates but does not prevent EMCV-stimulated nitric oxide (fig. 4) and nitric oxide is a known inhibitor of caspase-3 activity [34]. Consistent with antiapoptotic actions of PI3K activation, EMCV infection of macrophages does not increase caspase-3 activity in a statistically significant manner. Treatment of RAW264.7 cells with camptothecin, a topoisomerase inhibitor and apoptosis inducer, was used as a positive control for apoptosis and resulted in a 3 -fold increase in caspase- 3 activity (not shown). These findings suggest that PI3K plays a role in regulating the responses of macrophages to EMCV infection, with the activation of an inflammatory response when active and the induction of cell death by apoptosis when inactive. 


\section{Discussion}

The mechanisms responsible for determining the response of macrophages to virus infection have yet to be fully defined. The potential responses include the activation of inflammation, induction of classical antiviral responses and induction of cell death. We have shown that macrophages infected with EMCV, or treated with poly IC, respond by the rapid activation of signaling pathways that converge on the expression of inflammatory genes such as iNOS, COX-2, and IL-1 $[2,9,11,12,14]$. Chronologically, activation of inflammatory gene expression precedes induction of the classical type 1 IFN antiviral response that is associated the recognition of intracellular dsRNA $[14,35]$. In cells that fail to respond with activation of antiviral activity (inflammation or the type 1 IFN response), apoptosis is a potential outcome as this form of death represents a mechanism to remove a virally infected cell. PI3K plays a primary role as a regulator of cell viability as an antiapoptotic factor and previous studies using mouse embryonic fibroblast lacking $\mathrm{p} 85 \alpha$, a regulatory subunit of PI3K, have shown increased cell death following EMCV infection as compared to $\mathrm{p} 85 \alpha+/+$ cells [36]. Additional studies have also provided evidence for an antiapoptotic role for PI3K during Sendai virus infection [31].

In this study, the role that $\mathrm{PI} 3 \mathrm{~K}$ plays in regulating the response of macrophages to EMCV infection and poly IC treatment was examined. Using immuno-complex kinase assays and phosphorylation of the PI3K substrate Akt, we show that EMCV and poly IC stimulate the rapid activation of PI3K in macrophages. Chemical and molecular inhibition of PI3K results in an attenuation in the inflammatory response of macrophages to EMCV infection or treatment with dsRNA. The inflammatory genes inhibited include iNOS, COX-2 and IL-1 $\beta$. The inhibition of PI3K not only attenuates the expression of inflammatory genes, it also results in a change in the morphology of macrophages from activated to apoptotic. EMCV infection stimulates a macrophage morphology that is consistent with activation. This is evidenced by cell enlargement, formation of ruffled membranes and long dendritic-like processes (fig. 6). Alone, PI3K inhibitors do not modify the quiescent phenotype of naïve macrophages; however, in EMCV-infected macrophages PI3K inhibition is associated with an apoptotic morphology characterized by cell condensation and the loss of processes and ruffled membranes. The appearance of this apoptotic morphology is associated with a 2 -fold increase in caspase- 3 activity. These findings suggest that in the absence of PI3K activation, EMCV infection stimulates macrophage apoptosis, and when activated, the induction of a PI3K-directed antiviral response of inflammatory gene expression takes place. These findings support a central role for PI3K in the determination of the macrophage response to virus infection.

Several viruses have previously been shown to activate PI3K [16-19, 31]. From the perspective of the invading virus, activation or utilization of host PI3K may be to prevent host cell death in an effort to favor viral replication. Consistent with this view, Thomas et al. [18] have shown that respiratory syncytial virus activates PI3K in airway epithelial cells and inhibition of PI3K results in apoptosis. In addition, Johnson et al. [17] have shown that human cytomegalovirus activates PI3K in fibroblasts and inhibition of PI3K prevents viral replication. The role of PI3K during virus infection from the perspective of the host cell is not well defined. Our findings suggest that PI3K plays a primary role in the induction of inflammatory gene expression that may serve as a host cell defense of macrophages during virus infection. Inhibition of PI3K attenuates dsRNA- or EMCV-induced iNOS, COX-2 and IL-1 expression, nitric oxide production and the release of biologically active IL-1. These findings are in agreement with a regulatory role of PI3K in the production of nitric oxide and release of IL-1 from macrophages and the enhanced levels of virus load in animals deficient in iNOS [21].

The third response of infected cells is activation of type 1 IFN antiviral activities. The antiviral response is characterized the recognition dsRNA by receptors such as PKR [37, 38], melanoma differentiation-associated gene-5 (mda5) [39], retinoid-acid-inducible gene (RIG-I) [40] and TLR3 [41], induction of type 1 IFN expression, and induction of antiviral genes by these IFNs. We have shown that the inflammatory gene response of iNOS, COX-2 and IL-1 occurs by pathways that appear to be independent of classical dsRNA receptors such as PKR [9, 13, 14], TLR3 [12] and mda5 [manuscript in review]. In these studies, inhibition of inflammatory gene expression in response to EMCV infection does not modify type 1 IFN production, and inhibition of classical dsRNA receptors such as TLR3 does not modify the inflammatory gene response [12]. The signaling receptor activated by EMCV infection is currently unknown. EMCV capsid void of virus RNA is capable of activating mitogen-activated protein kinase (MAPK) and NF- $\kappa \mathrm{B}$ signaling pathways and iNOS expression, suggesting that the antiviral pathway of inflammatory gene expression does not require viral RNA accumulation or viral protein expression [14]. These findings suggest that EMCV capsid protein 
may activate MAPK and NF- $\kappa \mathrm{B}$ signaling pathways by interacting with a cell surface receptor. We are currently examining the potential role of G-protein-coupled receptors (GPCR) as potential regulators of inflammatory gene expression in response to EMCV infection. GPCR are known activators of PI3K and MAPK $[15,42]$ and, as shown in the current and our previous studies, PI3K and MAPK are required for inflammatory gene expression by macrophages in response to EMCV infection.

\section{Acknowledgements}

The National Institutes of Health grants DK52194 and AI44458 (J.A.C.) and a physician scientist award from the American Diabetes Association (WF) supported these studies.

\section{References}

1 Heitmeier MR, Scarim AL, Corbett JA: Double-stranded RNA-induced inducible nitricoxide synthase expression and interleukin-1 release by murine macrophages requires $\mathrm{NF}$ $\kappa \mathrm{B}$ activation. J Biol Chem 1998;273:1530115307.

-2 Steer SA, Moran JM, Maggi LB, Jr., Buller RM, Perlman H, Corbett JA: Regulation of cyclooxygenase- 2 expression by macrophages in response to double-stranded RNA and viral infection. J Immunol 2003;170: 1070-1076.

$>3$ Karupiah G, Xie QW, Buller RM, Nathan C, Duarte C, MacMicking JD: Inhibition of viral replication by interferon- $\gamma$-induced nitric oxide synthase. Science 1993;261:14451448.

4 Saura M, Zaragoza C, McMillan A, Quick RA, Hohenadl C, Lowenstein JM, Lowenstein CJ: An antiviral mechanism of nitric oxide: inhibition of a viral protease. Immunity 1999;10:21-28.

5 Lowenstein CJ, Hill SL, Lafond-Walker A, Wu J, Allen G, Landavere M, Rose NR, Herskowitz A: Nitric oxide inhibits viral replication in murine myocarditis. J Clin Invest 1996;97:1837-1843.

$\checkmark 6$ Flodstrom M, Horwitz MS, Maday A, Balakrishna D, Rodriguez E, Sarvetnick N: A critical role for inducible nitric oxide synthase in host survival following coxsackievirus B4 infection. Virology 2001;281:205215.

7 Steer SA, Corbett JA: The role and regulation of COX-2 during viral infection. Viral Immunol 2003; 16:447-460.

8 Iordanov MS, Paranjape JM, Zhou A, Wong J, Williams BR, Meurs EF, Silverman RH, Magun BE: Activation of p38 mitogen-activated protein kinase and c-Jun $\mathrm{NH}_{2}$-terminal kinase by double-stranded RNA and encephalomyocarditis virus: Involvement of RNAse 1, protein kinase $\mathrm{R}$, and alternative pathways. Mol Cell Biol 2000;20:617-627.

$>9$ Maggi LB, Jr., Moran JM, Buller RM, Corbett JA: Erk activation is required for doublestranded RNA- and virus-induced interleukin-1 expression by macrophages. J Biol Chem 2003;278:16683-16689.
10 Liou HC, Baltimore D: Regulation of the $\mathrm{NF} \kappa \mathrm{B} / \mathrm{Rel}$ transcription factor and IкB inhibitor system. Curr Opin Cell Biol 1993;5: 477-487.

11 Maggi LB, Jr., Moran JM, Scarim AL, Ford DA, Yoon JW, McHowat J, Buller RM, Cor bett JA: Novel role for calcium-independent phospholipase $\mathrm{a}_{2}$ in the macrophage antiviral response of inducible nitric-oxide synthase expression. J Biol Chem 2002;277: 38449-38455.

12 Steer SA, Moran JM, Christmann BS, Maggi LB, Jr., Corbett JA: Role of MAPK in the regulation of double-stranded RNA- and encephalomyocarditis virus-induced cyclooxygenase-2 expression by macrophages. J Immunol 2006;177:3413-3420.

13 Maggi LB, Jr., Heitmeier MR, Scheuner D, Kaufman RJ, Buller RM, Corbett JA: Potential role of PKR in double-stranded RNA-induced macrophage activation. EMBO J 2000; 19:3630-3638.

14 Moran JM, Moxley MA, Buller RM, Corbett JA: Encephalomyocarditis virus induces PKR-independent mitogen-activated protein kinase activation in macrophages. J Virol 2005;79:10226-10236.

15 Vanhaesebroeck B, Leevers SJ, Ahmadi K, Timms J, Katso R, Driscoll PC, Woscholski R, Parker PJ, Waterfield MD: Synthesis and function of 3-phosphorylated inositol lipids. Annu Rev Biochem 2001;70:535-602.

16 Mannova P, Beretta L. Activation of the $\mathrm{N}$ Ras-PI3K-Akt-mTOR pathway by hepatitis c virus: Control of cell survival and viral replication. J Virol 2005;79:8742-8749.

17 Johnson RA, Wang X, Ma XL, Huong SM, Huang ES: Human cytomegalovirus up-regulates the phosphatidylinositol 3-kinase (PI3-K) pathway: inhibition of PI3-K activity inhibits viral replication and virus-induced signaling. J Virol 2001;75:6022-6032.

18 Thomas KW, Monick MM, Staber JM, Yarovinsky T, Carter AB, Hunninghake GW: Respiratory syncytial virus inhibits apoptosis and induces NF- $\mathrm{KB}$ activity through a phosphatidylinositol 3-kinase-dependent pathway. J Biol Chem 2002;277:492-501.
19 Buchkovich NJ, Yu Y, Zampieri CA, Alwine JC: The torrid affairs of viruses: Effects of mammalian DNA viruses on the PI3K-AktmTOR signalling pathway. Nat Rev Microbiol 2008;6:266-275.

20 Cooray S: The pivotal role of phosphatidylinositol 3-kinase-Akt signal transduction in virus survival. J Gen Virol 2004;85:10651076.

-21 Weinstein SL, Finn AJ, Dave SH, Meng F, Lowell CA, Sanghera JS, DeFranco AL: Phosphatidylinositol 3-kinase and mTOR mediate lipopolysaccharide-stimulated nitric oxide production in macrophages via interferon- $\beta$. J Leukoc Biol 2000;67:405-414.

-22 Hara K, Yonezawa K, Sakaue H, Ando A, Kotani K, Kitamura T, Kitamura Y, Ueda H, Stephens L, Jackson TR, et al.: 1-Phosphatidylinositol 3-kinase activity is required for insulin-stimulated glucose transport but not for Ras activation in CHO cells. Proc Natl Acad Sci USA 1994;91:7415-7419.

23 Beckerman KP, Rogers HW, Corbett JA, Schreiber RD, McDaniel ML, Unanue ER: Release of nitric oxide during the T cell-independent pathway of macrophage activation. Its role in resistance to Listeria monocytogenes. J Immunol 1993;150:888-895.

24 Bae YS, Eun HM, Yoon JW: Genomic differences between the diabetogenic and nondiabetogenic variants of encephalomyocarditis virus. Virology 1989;170:282-287.

25 Phillips-Mason PJ, Raben DM, Baldassare JJ: Phosphatidylinositol 3-kinase activity regulates $\alpha$-thrombin-stimulated G1 progression by its effect on cyclin D1 expression and cyclin-dependent kinase 4 activity. J Biol Chem 2000;275:18046-18053.

26 Green LC, Wagner DA, Glogowski J, Skipper PL, Wishnok JS, Tannenbaum SR: Analysis of nitrate, nitrite, and [15N]nitrate in biological fluids. Anal Biochem 1982;126:131-138.

27 Hill JR, Corbett JA, Kwon G, Marshall CA, McDaniel ML: Nitric oxide regulates interleukin 1 bioactivity released from murine macrophages. J Biol Chem 1996;271:2267222678. 
28 Arnush M, Scarim AL, Heitmeier MR, Kelly $\mathrm{CB}$, Corbett JA: Potential role of resident islet macrophage activation in the initiation of autoimmune diabetes. J Immunol 1998;160: 2684-2691.

29 Sarbassov DD, Guertin DA, Ali SM, Sabatini DM: Phosphorylation and regulation of Akt/ PKB by the rictor-mTOR complex. Science 2005;307:1098-1101.

30 Hibbs JBJ, Vavrin TR, Granger Z, Drapier DL, Amber JC, Lancaster JR Jr: Synthesis of nitric oxide from a terminal guanidino nitrogen atom of L-arginine: a molecular mechanism regulating cellular proliferation that targets intracellular iron; in Moncada HE (ed): Nitric Oxide from L-Arginine: A Bioregulatory System. New York, Elsevier Science, 1990, pp 189-223.

31 Tyner JW, Uchida O, Kajiwara N, Kim EY, Patel AC, O'Sullivan MP, Walter MJ, Schwendener RA, Cook DN, Danoff TM, Holtzman MJ: CCL5-CCR5 interaction provides antiapoptotic signals for macrophage survival during viral infection. Nat Med 2005;11: $1180-1187$.
Song G, Ouyang G, Bao S: The activation of Akt/PKB signaling pathway and cell survival. J Cell Mol Med 2005;9:59-71.

33 Boatright KM, Salvesen GS: Mechanisms of caspase activation. Curr Opin Cell Biol 2003; 15:725-731.

34 Rossig L, Fichtlscherer B, Breitschopf K, Haendeler J, Zeiher AM, Mulsch A, Dimmeler S: Nitric oxide inhibits caspase-3 by S-nitrosation in vivo. J Biol Chem 1999;274: 6823-6826.

35 Samuel CE: Antiviral actions of interferons. Clin Microbiol Rev 2001;14:778-809, table of contents.

36 Prejean C, Sarma T, Kurnasov O, Usacheva A, Hemmings B, Cantley L, Fruman DA, Morrison LA, Buller RM, Colamonici OR: Phosphatidylinositol 3-kinase confers resistance to encephalomyocarditis and herpes simplex virus-induced cell death through the activation of distinct downstream effectors. J Immunol 2001;167:4553-4559.

37 Meurs E, Chong K, Galabru J, Thomas NS, Kerr IM, Williams BR, Hovanessian AG: Molecular cloning and characterization of the human double-stranded RNA-activated protein kinase induced by interferon. Cell 1990;62:379-390.
Clemens MJ, Elia A: The double-stranded RNA-dependent protein kinase PKR: structure and function. J Interferon Cytokine Res 1997; 17:503-524.

39 Gitlin L, Barchet W, Gilfillan S, Cella M, Beutler B, Flavell RA, Diamond MS, Colonna M: Essential role of mda-5 in type I IFN responses to polyriboinosinic:polyribocytidylic acid and encephalomyocarditis picornavirus. Proc Natl Acad Sci USA 2006;103: 8459-8464.

40 Yoneyama M, Kikuchi M, Natsukawa T, Shinobu N, Imaizumi T, Miyagishi M, Taira K, Akira S, Fujita T: The RNA helicase RIG-I has an essential function in double-stranded RNA-induced innate antiviral responses. Nat Immunol 2004;5:730-737.

41 Alexopoulou L, Holt AC, Medzhitov R, Flavell RA: Recognition of double-stranded RNA and activation of NF- $\kappa$ B by Toll-like receptor 3. Nature 2001;413:732-738.

-42 Sotsios Y, Ward SG: Phosphoinositide 3-kinase: A key biochemical signal for cell migration in response to chemokines. Immunol Rev 2000;177:217-235. 